\section{Der Weg ins Spital}

E. Taverna

Wo es noch Natur gibt und keine Verkehrswege, geschieht die Triage unterwegs. Nur die Zähesten kommen durch, nur wer marschieren kann oder die Schlaglöcher der Pisten und die harte Ladefläche eines Lastwagens übersteht. Ausserhalb der sogenannten dritten Welt ist das heute kein Problem. Der moderne Urlauber verlässt sich auf die Rega, wird mit dem Jet nach Hause geholt und aus der steilsten Felswand ausgeflogen. Die Ambulanzen grösserer Spitäler gleichen mobilen Intensivstationen, reichlich bestückt mit Notfallärzten und Rettungssanitätern.

Der Weg ins Spital ist bei uns höchstens noch ein Problem für Katastrophenfälle und Kriegsszenarien. Wenn die Mittel wieder knapp werden, wird das Selbstverständliche zur Knacknuss für Krisenstäbe und die Zeit wird zum Gegner. Im zivilen Alltag möchte der Interverband für Rettungswesen IVR jeden Patienten innert dreissig Minuten in einer Klinik haben. Für den viel geprobten Ernstfall soll jeder und jeder Verletzte innerhalb von sechs Stunden in einer sanitätsdienstlichen Einrichtung versorgt sein.

In alten Zeiten, vor der grossen Beschleunigung, haben wir in Gebirgskursen die Patienten auf Maultiere festgebunden. Auf den warmen Flanken gut genährter Traintiere wurden die Unglücklichen ordonanzgemäss "gebastet" und in Militärdecken gewickelt, über Stock und Stein talwärts geschüttelt. Beliebte Tragarten wie der "Gamsbock" oder Gefechtsschlitten mit Rollgestell und Bahre ersetzten den Sanitätern die heutigen Kraftmaschinen. Wer vom Schicksal begünstigt war, wurde moulagiert in den Wagen der Rhätischen Bahn in die Militärspitäler von Disentis und Davos transportiert. Das Umrüsten dieser Waggons und die ausserfahrplanmässigen Ausweichmanöver haben mehrere Generationen Schweizer Männer für das Problem der Verwundetentransporte sensibilisiert.

Leserinnen und Leser, auch solche ohne die erwähnte militärische Erziehung, werden das schön gestaltete Buch "Im Kalberwägeli zum Spital» von Roger Gonzenbach zu schätzen wissen. Der langjährige Chirurgie-Chefarzt des Kantonsspitals Frauenfeld hat aus seinen Funden in Staats-, Gemeinde- und Kirchenarchiven ein Stück Thurgauergeschichte des 19. Jahrhunderts rekonstruiert. "Abschiebung ins Spital und Krankentransport» nennt der Untertitel das akribisch recherchierte Werk über den mühsamen Weg vom Domizil des Kranken in die Heime, Asyle, Armenhäuser und Irrenanstalten. Holperig waren nicht nur die Wege für die Fuhrwerke und Ambulanzen, voller Fallgruben war auch das Kompetenzgerangel um eine Aufnahmeerlaubnis. Zu den Reichen kam der Arzt nach Hause. In die Spitäler wurden, ausser den chirurgischen Notfällen, die Armen für Kost und Logis und einfache Pflege gebracht. Die Insassen waren almosengenössige Angehörige, Sozialfälle, Menschen mit Krätze, die wieder einmal richtig gebadet wurden

Das Finanzdepartement entschied, damals wie heute. Bis die Regierung nach Vorliegen der Steuer-, Personal- und Vermögensauskünfte, nebst Arztzeugnis, beschloss, vergingen Tage. Vor allem während der häufigen Pocken- und Choleraepidemien eskalierte der Streit zwischen einweisenden Hausärzten, Spitalärzten und der Regierung. Gemeinden und Regionen organisierten die Transporte selber. Sie schlossen Fahrverträge mit Fuhrhaltern ab, die bei Seuchen ein gutes Geschäft machten, da sie zusätzlich für die Desinfektion entschädigt wurden. Erst 1914 machte das Krankenautomobil der Firma Saurer der Pferdeära ernsthafte Konkurrenz. Nach der Grippewelle von 1918 begann die allgemeine Motorisierung. Mit dem Ausbau der Eisenbahn schien selbst eine Verlegung nach Zürich attraktiv. Ein Wort wie "outsourcen» war noch unbekannt, aber die Idee war schon da. Im Güterwagen bezahlte der Arme pro Bahnstunde einen Franken. Im Personenwagen mit Abtrittlokal war es entsprechend teurer. Die verschiedenen Bahnsysteme erforderten Wagenwechsel und die Nationalbank machte 1878 Konkurs. Die Bahn erwies sich für das Gesundheitswesen als ungeeignet. Vielleicht wendet sich das Blatt wieder zugunsten der Schiene, wenn die 1999 mit Sponsorengeldern eingerichtete Haltestelle bei der psychiatrischen Klinik Münsterlingen rege benützt wird.

Länger als einen Tag war auch vor 100 Jahren niemand unterwegs. Dafür dauerte ein Spitalaufenthalt Monate bis Jahre. Inzwischen hat sich alles weiterentwickelt, auch die Bürokratie.

Roger Gonzenbach: Im Kälberwägeli zum Spital. Frauenfeld: Huber \& Co. AG; 2000. 112 Seiten. 